\title{
A Comprehensive Review on the Effectiveness of Existing Noise Barriers commonly used in the Railway Industry
}

\author{
Shahiron Shahidan ${ }^{1, a}$, Nurul Izzati Raihan Ramzi Hannan ${ }^{1}$, Mohamad Zulkhairi Md Maarof ${ }^{2}$, Alif Syazani Leman ${ }^{1}$ and \\ Mohamad Syamir Senin ${ }^{1}$ \\ ${ }^{1}$ Faculty of Civil and Environmental Engineering, Universiti Tun Hussein Onn Malaysia, 86400 Batu Pahat, Johor, Malaysia. \\ ${ }^{2}$ Faculty of Engineering Technology, Universiti Tun Hussein Onn Malaysia, 86400 Batu Pahat, Johor, Malaysia.
}

\begin{abstract}
Nowadays, advanced development and sophisticated new technology have led to various types of environmental pollution such as water, air, land, thermal pollution and so on. Recently, however, noise pollution is becoming one of the major threats to the world especially in urban areas where it adversely affects the quality of life of the public. In Malaysia, the Department of Environment has identified that the average transportation noise levels in major cities in peninsular Malaysia are $71.6 \mathrm{~dB}(\mathrm{~A})$ and $70.4 \mathrm{~dB}(\mathrm{~A})$ during the day and night respectively. The noise is usually emitted by airplanes, trains, vehicles, motorcycles, trucks and etc. Even though rail transport requires less energy and emits less hazardous substances, it has contributed to noise pollution issues and several health hazards among urban inhabitants such as deafness, nervous breakdowns, mental disorder, heart troubles, high blood pressure, headaches, dizziness, inefficiency and insomnia. Therefore, many studies attempt to reduce noise pollution by applying noise barriers at noise polluted areas via various approaches. This paper aims to explore the effectiveness of noise barriers using noise absorption performance due to several factors such as type of absorbent materials, material thickness, density, porosity and design. This research has found that the thicker the specimen and the denser the absorbent material, the better the sound absorption performance. Besides that, barrier design also plays a major role in determining its effectiveness, where the effectiveness of noise barriers should be high and long enough to break the line-of-sight between the sound source and the receiver. There are several methods that can be used to measure the effectiveness of noise barriers such as the Adrienne Method (in-situ measurement method) and impedance tube method (laboratory measurement method) to measure the acoustic absorption. Nevertheless, the impedance tube measurement method provides the most precise results with the least measurement uncertainty as it only required small samples of the material.
\end{abstract}

\section{Introduction}

In a densely populated city with many high-rise buildings, noise pollution is one of the environmental problems that has been addressed with high priority [1]. A rapidly increasing population around the world accompanied by increasing consumption and a developing economy continue to generate noise pollution, where almost $80 \%$ of city traffic noises come from vehicles such as trains, cars, buses and motorcycles which are the major sources of noise in a modern environment. According to H. B. Huang et. al [2], there are various sources which contribute to vehicle noise which including axle-gear, tires, wind and engine. Meanwhile, Pultznerov and Izvolt [3] has identified railways as one of the most important modes of transportation for developed countries such as Korea, Japan and etc. Nowadays, rail transport has contributed to the biggest environmental noise issue even though it requires less energy and emits less hazardous substances [4]. Based on Comision \& Energy [5], railways noise originates from the rolling noise, noise from traction,

\footnotetext{
${ }^{\text {a }}$ Corresponding author: shahironshahidan@gmail.com
}

auxiliary system and aerodynamic noise. Noise is primarily defined as "disagreeable or undesired sound" or other disturbance. Bruneau [6] has indicated that noise and sound are constituted in the same phenomenon of atmospheric pressure fluctuations about the mean atmospheric pressure, where the differentiation is greatly subjective.

According to Hanidza et al. [7], the average level of sound pressure at night of $40 \mathrm{~dB}$ and $55 \mathrm{~dB}$ as an interim target should be the target to be achieved in order to prevent nocturnal noise deleterious health consequences which is recommended by the WHO regional office for Europe. In Malaysia, the Department of Environment has identified that the average transportation noise levels in major cities in peninsular Malaysia are $71.6 \mathrm{~dB}(\mathrm{~A})$ and $70.4 \mathrm{~dB}$ (A) during the day and night respectively. However, a noise level above $55 \mathrm{~dB}(\mathrm{~A})$ is considered as noise pollution [8]. If noise above this level lasts for an extended period of time, the efficiency and well-being of a person will be reduced [9].

Noise pollution issues have reduced the quality of life of human beings. Bistrup et al.[10] found that the 
exposure of noise to humans depends on the emission of sound, how the sound is received by the human body and the setting for the emission and perception of sound. Noise in the range of 65 to $75 \mathrm{~dB}$ (A) causes stress to the body, which can lead to arterial hypertension (high blood pressure), cardiovascular disease and myocardial infarction (heart attack) [11-13]. Besides that, the highest level of noise will also reduce gastric secretion and cause stomach ulcers [14].

Popović et al. [15] have listed several health problems caused by noise such as uneasiness, irritability, tendency towards depression, insomnia, digestive problems, cardio-vascular diseases and deafness. Even though noise can be classified as a slow and subtle killer, it could also be so severe that it may lead to permanent loss of memory or a psychiatric disorder [16-18]. Therefore, many studies on noise pollution using different approaches are actively being conducted at the moment [19][20].

In order to reduce noise pollution caused by noise from rail transport and to protect the health and the quality of life of people living close to railroads, noise barriers could be used as it is considered as one of the best noise reduction devices. Maffei and Luigi [21] also stated that noise barriers are the main solution for noise mitigation and very often provides a good insulation. All related devices that act on airborne sound propagation (road/rail covers, claddings and added devices) are collectively called Noise Reducing Devices (NRDs) [22].

Noise barrier is a structure that is built between a noise source and a receiver which may be living or nonliving. However, there are several types of materials that could be used for noise barriers such as wood, concrete, masonry, metal, gabion and transparent materials [23], where the materials used for barriers must be of an impervious material with a minimum surface density of 4lb/sq. $\mathrm{ft}$ to ensure that the noise barrier is effective for reducing noise levels. The effectiveness of certain noise barriers is determined by its dimensions and material used, where the noise barrier should have a transmission loss of at least $10 \mathrm{~dB}$ (A) greater than desired noise reduction[24]. Though the noise barrier could mitigate or reduce the noise level, it cannot block the noise from the source to the receiver completely. However, the evaluation of effectiveness of noise barriers could be determined by using the insertion loss method which is defined as differences between the measured sound pressure levels behind existing barriers and without barriers [25]. However, little emphasis has been placed on the evaluation of the effectiveness of noise barriers. This, this paper aims to determine the effectiveness of different types of existing noise barriers in the industry in terms of materials used, parameters and shapes identified by using the insertion loss method.

\section{Methodology}

According to P. Guidorzi and M. Garai [26], several methods can be used to determine the effectiveness of noise barriers. The Adrienne method is one of the methods that can be used to measure in-situ sound reflection, diffraction and airborne sound insulation. N. D Jambrosic [27] has indicated that the Adreienne method (in-situ measurement method) has been developed to measure the acoustic absorption or reflection coefficients in-situ, where this method uses one single-driver loudspeaker and one microphone in a fixed position from the loudspeaker. However, this method also has two measurements systems; in-situ measurement absorption coefficient and the second method which is basically similar to the first method, but it is used with the multiplication of impulse responses with the ratio between the estimated time of the arrival of the direct incoming sound impulse and the estimated time of the reflected incoming sound impulse (used in some commercial acoustic measurement application) such as Easera software [27] as shown in Figure 1 and Figure 2. Both systems introduce significant harmonic distortion but the Adrienne method produces less harmonic distortion than second method.

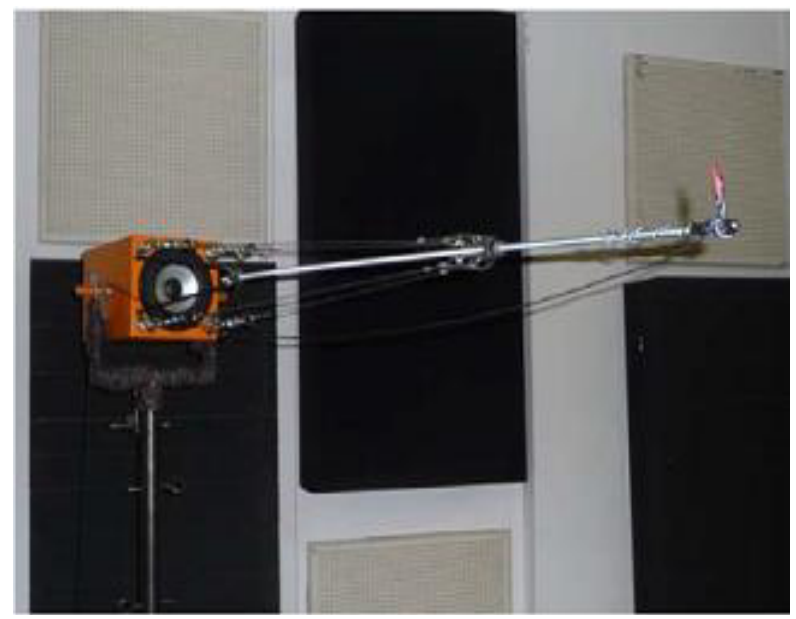

Figure 1: Configuration of the Adrienne method for in-situ measurement of the absorption coefficient.

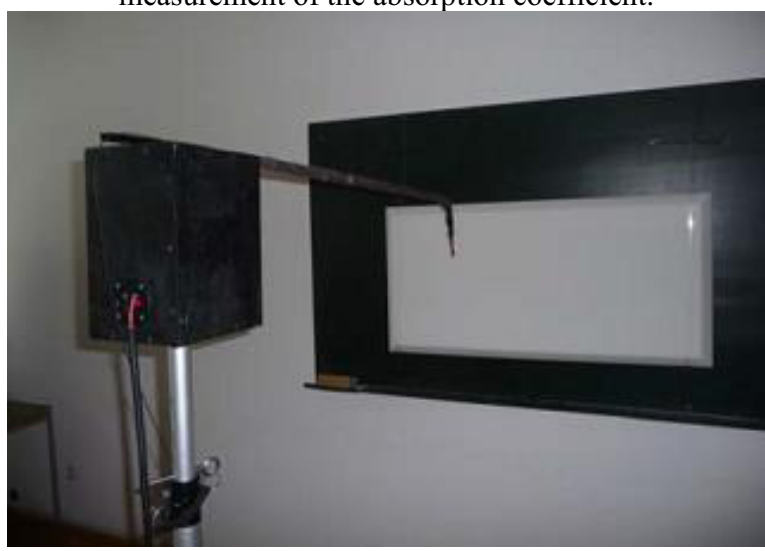

Figure 2: Configuration of the second method

Sound sources emitted the sound wave in both methods that travel past the microphone position to the device under the test and are then reflected on it [27]. The surface undergoing the test can be an absorbing material such as noise barrier material to determine its absorption coefficient. A hard surface with a absorption coefficient of less than 0.05 is selected as a reference to be compared with the tested material. Figure 3 shows the measurement set up. The source and the microphone are $125 \mathrm{~cm}$ apart 
and the microphone is placed $25 \mathrm{~cm}$ away from the measured surface.

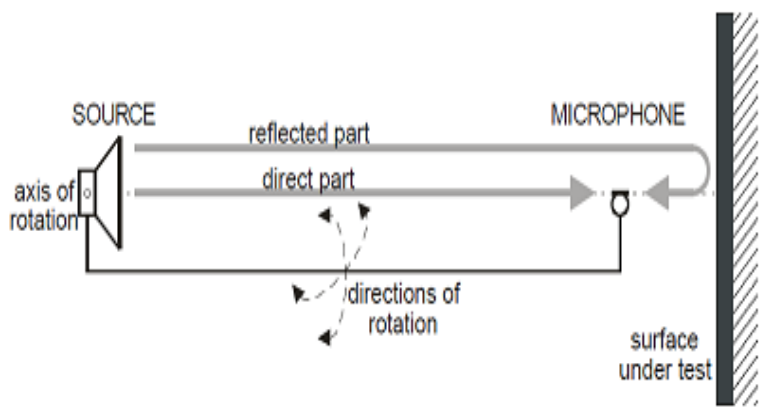

Figure 3: Measurement set up

The signal subtraction technique is used to separate the direct component and the reflected component by extracting the reflected component from the overall impulse response after the direct component is removed by subtracting the identical signal. For the Adrienne method, the reflected part of the impulse is being multiplied with time due to the longer time taken compared to the direct part. Meanwhile, for the second method, the correction factor is obtained by dividing the arrival time of the reflected component with the arrival time of the direct component [27]. Figure 4 shows the direct comparison of measurement between the two methods which is between the Adrienne method and the Easera software. It is obvious that the absorption coefficient is higher when the sound travels at a greater angle due to the thicker area of absorption material.

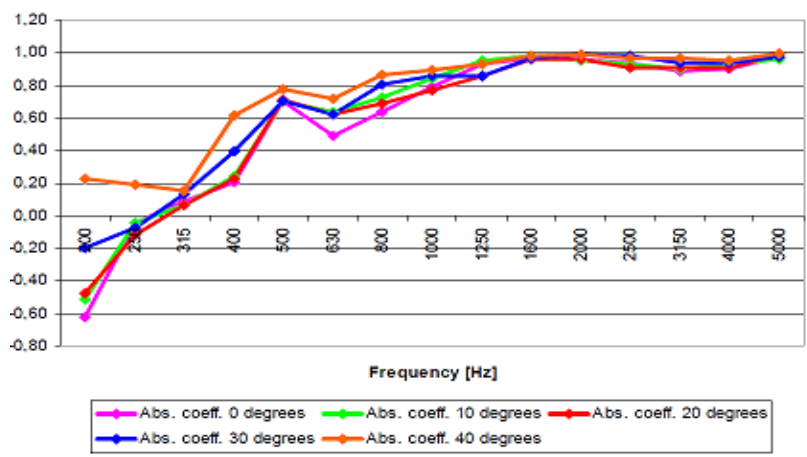

Figure 4: Absorption coefficient measured for various angles of incidence

Both methods are compared and they show a good agreement if the measured absorption coefficient is very high, but it shows disagreement for the lower values [27]. Besides that, laboratory measurement method also can been conducted in order to determine accurate measurement of the normal incident acoustic impedance and requires just a small sample of absorbing material to be tested, which used a standing wave tube or called as the impedance tube method (as shown in Figure 5). Using this method, acoustic waves produced by a loud speaker travel down a pipe and are reflected from the test sample. The standing wave pattern in the pipe is formed by the phase interference between the waves which are incident upon and reflected from the test sample material. The incident and reflected waves are considered to have the same amplitude if $100 \%$ of the incident wave is reflected. The incident and reflected wave have different amplitudes when some of the incident wave energy is absorbed by the test material. During the test, the sound source is moved towards the specimen and the first sound pressure level minimum is detected and the corresponding voltage is read off the measurement amplifier.

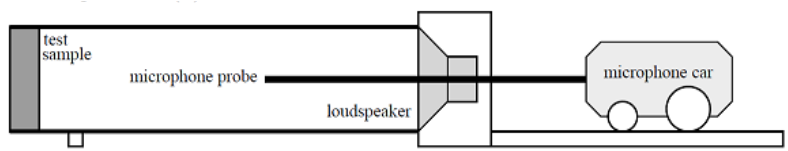

Figure 5: Standing wave impedance tube

According to C. Heed [28], the incidence sound absorption coefficient can be determined based on the ratio of the maximum and the minimum voltage corresponding to the measurements of the maximum to minimum sound pressure levels used to calculate the incidence sound. Therefore, it can be concluded that all methods listed are accurate measurements that have been used to measure the effectiveness of noise barriers. Nonetheless, the in-situ measurements of the absorption coefficient like the first and second method are not easy to carry out due to unfavourable measurement conditions. In addition, the main limitation of all systems based on the pass-by method and Adrienne method is the geometry of the measuring space [27], even though it is more economical in terms of measurement equipment and easy to be implemented. So, it can be concluded that the impedance tube measurement method provides the most precise results with the least measurement uncertainty where it only requires small samples of the materials to be measured either by using the standing wave ratio for discrete frequencies or by using transfer functions between two fixed points inside the tube where the pressure is measured using equalized microphones.

\section{Noise Barrier Material and Design}

\subsection{Sound absorption material}

For the last few decades, sound absorption materials have been used for reducing noise and reducing echoes in enclosed spaces [29]. Usually, absorptive materials such as porous materials are always used to reduce the reflection of sound by controlling airborne sounds. Besides that, there are several types of material which have the potential to absorb sound from several sources such as porous absorptive materials, fibrous materials and lightweight materials. Generally, porous materials are classified as fibrous medium or porous foam which is produced using various types of materials. On the other hand, fibrous media consists of high acoustics absorption and fire proof properties for several materials such as glass or rock wool [30-33]. According to T. Morimoto [34], more than $90 \%$ of air on porous absorbing materials leads to the dissipation of sound propagation through the small pores on the porous material. The performance of conventional absorbers depends on the pores and fibre 
structure. Conventional sound absorption materials can be expensive. However, nowadays many researchers are interested to take a similar approach in the development of sustainable sound absorbers by using waste material which has created environmental pollution.

Due to the abundance of waste materials, many researchers have taken innovative steps by exploring the potential of a variety of material as sound barriers. A. Amanda et al. [35] have investigated the potential of sugarcane bagasse for sound absorption application. Here, the comparison was done between three types of panels with and without sugarcane bagasse. The potential of coir as agriculture waste has also been investigated [36]. It was found that coir with the addition of recycled rubber is capable of absorbing sound with an average of 0.6 (sound absorption coefficient) which is caused by filler content. S. Ersoy and H. Küçük [37] have also investigated the sound absorption performance by using tea-leaf fibre and found the comparison between the different configuration of tea-leaf fibre with and without backing provided by a single layer of woven textile cloth. Meanwhile, H. K. Kim and H. K. Lee [38] have investigated the influence of lightweight aggregates on the acoustics properties of porous concrete due to different layers. The result has shown that the sound absorption coefficient for porous concrete has achieved the maximum value which is approximately 1.00 . The minimum absorption coefficient of the 'double-layered porous concrete' structure is shown to be more than 0.60 with a frequency of $400 \mathrm{~Hz}$ or above, considering the tolerant error.

Therefore, acoustical material plays an important role in acoustics engineering in reducing the noise levels in various field. Usually, sound absorptive material is used to overcome unwanted effects of sound reflection and is also helpful in reducing the reverberation noise level [39]. Hence, the selection of sound absorbing materials was done based on several factors that will be discussed in this paper.

\subsection{Factors influencing acoustics performance}

Many researchers have conducted studies on the acoustics performance of noise barriers by using various types of sound absorptive materials. They have found several factors that will influence the absorption performance of noise barriers such as the types of materials, thickness, density, placement or position of the sound absorptive medium (noise barriers), compression, porosity and etc [29]. However, in this paper only six physical factors that have the greatest potential to influence the acoustics performance of noise barriers which are choice of materials, size of materials, porosity, thickness, density and design will be discussed.

\subsection{Choice of materials}

Noise barriers can be divided into reflective types, absorptive types, earth landscape and mixed types. Table 1 shows the details of each type mentioned.
TABLE 1: Types of noise barriers [24]

\begin{tabular}{|c|c|}
\hline Types & Descriptions \\
\hline Reflective type & $\begin{array}{c}\text { Transparent and non- } \\
\text { transparent }\end{array}$ \\
\hline Absorptive type & $\begin{array}{c}\text { Sound absorbent materials and } \\
\text { possible finishes of absorptive } \\
\text { panels }\end{array}$ \\
\hline Earth landscape & $\begin{array}{c}\text { Nature landscaped mound and } \\
\text { retaining structures }\end{array}$ \\
\hline Mixed type & A combination of all types \\
\hline
\end{tabular}

Despite the categorization in Table 1, the noise barriers are often divided into two groups which are either reflective or absorptive. The Environmental Impact Assessment (EIA) and Noise Impact Assessment (NIA) already determined the types of noise barriers such as reflective noise barriers, absorptive noise barriers or a combination of both.

\subsection{Size of materials}

The diameter of materials is one of the most important factors that need to be considered as it will influence the absorption coefficient during the test. According to Kouzumi et al.[40], the increase in fiber diameter tend to increase the coefficient of sound absorption as the movement of sound waves in thinner fibres occur more easily compared to thicker fibre. Meanwhile, P. R. Tahir et al, [36] used $5 \mathrm{~mm}$ to $10 \mathrm{~mm}$ of recycled rubber particles as additional material and 10 to $20 \mathrm{~mm}$ of coir fibre in the mixture of composite boards with different percentages of fillers. It was found that the increase in the percentage of coconut coir up to $20 \%$ is suitable to be made as sound absorbing material due to the good properties of coconut coir which are cellular, light and porous. A. Putra et al. [41] conducted a study on sugarcane wasted fibres as a sustainable acoustic absorber with a diameter of 5 to $10 \mathrm{~mm}$ in length and it was found that sugarcane absorbers that possess $1 / 2$ inch in thickness affects the acoustical performance which is better than commercial sound absorptive material. Moreover, the size of materials will also influence the acoustic absorption. H. K. Kim and H. K. Lee [38] discovered that 4 to $19 \mathrm{~mm}$ of aggregates have resulted in low absorption coefficients. This was due to a decrease in airflow resistance by means of friction of viscosity through the vibration of the air.

\subsection{Thickness}

Stein and Reynolds [42] concluded that the thickness of absorbent material is one of the important parameters that will affect the acoustic properties. A study on the acoustical performance of oyster shells has been conducted by E. Setyowati and G. Hardiman [43], with various dimensions of the samples which were tested to determine the absorption coefficient or sound transmission loss at $500 \mathrm{~Hz}$ to $1000 \mathrm{~Hz}$. From the studies, it was found that the mixture with a thickness of $1 \mathrm{~cm}$ containing oyster shells and white cement has the largest 
potential to absorb sound. Meanwhile, A. Putra et al. [41] also investigated the effect of the thickness of an innovative absorbent made from tea leaf fibre and it was found that the sound absorption coefficient of tea leaf fibre with a thickness of $10 \mathrm{~mm}$ is similar when compared with traditional absorbers such as polyester. The increase in sound absorption was due to the increase in sample thickness. Thicker samples will absorb more sound due to a longer travel distance by the impinged wave which causes it to lose more energy [44]. Besides that, H. K. Kim and H. K. Lee [45] discovered that the arrangement of material such as aggregates as absorbent material will affect the thickness of air gaps in panels. A decrease in frequency occurred due to the increasing thickness of the specimen. However, according to E. M. Samsudin et al. [29], the amount of absorption is not always proportional to the thickness of the absorbent material. It also depends on the type of materials and method of installation.

\subsection{Density}

The best sound absorption behavior depends on the density of the material which it is an important factor that needs to be considered in a research. According to A. Putra et al. [46], increasing amounts of sound absorber material added into a mixture will increase its density and subsequently improve the absorption at a higher frequency. Besides that, the density of absorptive material has shown an effect on flow resistivity. By adding the amount of absorption material into a mixture, the pores will become closer to each other which ultimately reduce the absorption capability. Meanwhile, L. Peng et al. [30] found that when the density of composite decreases, the acoustic wave reflection will be reduced due to the presence of larger voids (pores) inside the material.

Therefore, the acoustic waves in a less dense material will propagate more easily compared to denser material. In addition, the frictional and viscous resistance among the air particles and fibers inside the composite will also decrease due to the internal surface area [47-49]. Thus, most denser materials absorb more sound energy compared to less dense materials. However, in some cases, materials with higher density will absorb less sound energy due to non-fibrous characteristics of the materials. Materials that are more compact and dense are low in porosity which significantly affects its sound absorption performance

\subsection{Porosity}

Porosity is also an important factor that should be considered in this research. E. M. Samsudin et al. [29] has defined porosity as the ratio of the volume of voids to the total volume of the samples. By knowing the density of absorbent material, several methods can be used to identified the porosity of a particular absorbent material; dynamic method, static method and also by simple calculation [50]. Z. Hong et al. [51] have studied porosity by using several types of polymer perforated panels with different pore size and found that a panel containing rubber particles with a thickness of $3 \mathrm{~mm}$ and pore size of $5 \mathrm{~mm}$ has a porosity of $4.75 \%$. From the research, it is obvious that the porosity eventually affects the sound absorption performance of samples. The rubber particles have improved the sound absorption ability just like traditional porous materials such as PU foam or glass wool. According to S. Mahzan et al. [52], the absorbency of $60 \%$ recycled rubber will increase the porosity value up to $98.62 \%$ while a specimen with $100 \%$ recycled rubber has shown a reduction in porosity which is $86.59 \%$. Therefore, it can be said that a higher content of absorbent material in a sample will fill up more voids and decrease the porosity of samples. In terms of absorption capability, when the porosity value is more than $70 \%$, the value of absorption will usually remain constant. H. S. Seddeq [53] suggests that enough pores on the surface of material will allow sound waves to penetrate the porous material for maximum energy dissipation by friction.

\subsection{Noise barrier design}

H. Berger et al. [2] also stated that there are various factors that need to be considered in the production of noise such as traffic noise, construction noise, underwater noise as well as environmental and structural factors. The existing noise pollution mitigation methods could be improved by improving materials, parameters and shapes of existing noise barriers. Therefore, the designs of barriers also play a major role in determining its effectiveness [23][24]. Many designs have been proposed including classic wall type barrier and gabions [8]. Covering a T-shape barrier with a layer of mineral wool type absorbent material (flow resistivity $r=20,000 \mathrm{Nsm}$ and thickness $\mathrm{T}=0.1 \mathrm{~m}$ ) could improve the performance of a single rigid barrier by $2.5 \mathrm{~dB}$ which is better than the performance of purely absorptive barriers [25]. The barrier must be high enough and long enough to break the line-of-sight between the sound source and the receiver [19]. Modification of the top edges of the noise barriers has been shown to be capable of increasing noise attenuation over that of a simple barrier of the same height [28]. However, the height of a noise barrier does not necessarily have to be too high but it can be as high as $3 \mathrm{~m}$ or $4 \mathrm{~m}$ [20][23]. Nevertheless, noise barriers which are too long and too high cause other problems such as loss of sunlight and visual impact [26]. Therefore, the low height of noise barriers is mostly suitable for trains as the noise produced mainly originates from the rail tracks and bogie areas, which are close to the ground.

\section{Conclusions}

Effective noise barriers are usually able to reduce noise levels by 5 to $10 \mathrm{~dB}(\mathrm{~A})$ and heavily depend on its dimensions as well as the location of the noise sources and the noise receivers [54-56] The ability of environmental noise barriers to reduce A-weighted noise levels depends on its design, materials, density of absorbent material, porosity and thickness [23]. A reduction as much as $5 \mathrm{~dB}(\mathrm{~A})$ in noise level produced can 
be achieved if the noise barrier surface density exceeds $20 \mathrm{~kg} / \mathrm{m} 2$ and possesses a height tall enough to break the line of sight from the road to the receiver. An additional $1.5 \mathrm{~dB}(\mathrm{~A})$ reduction can be achieved for each additional meter of height[23]. Therefore, some important remarks on this literature review for this research are:

1. The materials used to build certain noise barriers play a major role in reducing noise levels existing in a real situation. Different types of sound absorbent materials would result in different absorption coefficients.

2. The decrease in thickness and size of the absorbent material will affect the increase in the sound absorption coefficient.

3. Most of the findings show that denser materials will absorb more sound energy compared to less dense materials. However, when the density of the absorbent material is higher with low porosity, it will usually absorb less sound energy. Therefore, it can be concluded that density and porosity are related to each other.

4. Porosity influences the sound absorption performance of samples. Porosity decreases due to a high content of absorbent material which fills up more voids in a particular sample. However, some research has indicated that the absorption coefficient will remain constant when the porosity value is more than $70 \%$.

5. Barrier design also play a major role where effective noise barriers should be high and long enough to break the line-of-sight between the sound source and the receiver

6. Most of the previous studies believe that the choice of materials, size of materials, porosity, thickness, density and design will influence the acoustic performance of noise barriers.

7. Various methods can be used to measure the effectiveness of noise barriers such as the Adrienne Method (in-situ measurement method) and the impedance tube method (laboratory measurement method). These methods can be used to measure acoustic absorption. However, the Adrienne method is not easy to carry out due to unfavourable measurement conditions.

8. Therefore, the impedance tube measurement method provides the most precise results with the least measurement uncertainty where it only requires small samples of the material.

To sum up, very little research focuses on the application of noise barriers for the railway industry even though it is one of the biggest contributors to noise pollution. Therefore, this warrants further research on this matter.

\section{Acknowledgement}

The authors would like to thank Universiti Tun Hussein Onn Malaysia and fellowship for the UTHM Scholarship and GPPS (U448).

\section{References}

1. K. M. Li, M. K. Law, and M. P. Kwok, "Absorbent parallel noise barriers in urban environments," $J$. Sound Vib., vol. 315, no. 1-2, pp. 239-257,(2008).

2. H. B. Huang, R. X. Li, X. R. Huang, M. L. Yang, and W. P. Ding, "Sound quality evaluation of vehicle suspension shock absorber rattling noise based on the Wigner-Ville distribution," Appl. Acoust., vol. 100, pp. 18-25, (2015).

3. Pultznerová. A, and Ižvolt. L, "Structural Modifications, Elements and Equipment For Railway Noise Reduction", Procedia Engineering, (2014).

4. I. Tsukernikov, I. Shubin, N. Ivanov, and T. Nevenchannaya, "Features of railway noise rationing and assessment in housing estate territory in Russia," Procedia Eng., vol. 117, no. 1, pp. 362-367, (2015).

5. E. COmision and D. G. Energy, "Assessment Study on Rail Noise Abatement Measures," Evaluation, pp. 1-129, (2007).

6. M. Bruneau, "Fundamentals of Acoustics," Fundam. Acoust., (2010).

7. Hanidza, T. I. T., Jan, A. A. M., Abdullah, R., \& Ariff, M., A Preliminary Study of Noise Exposure among Grass Cutting Workers in Malaysia. Social and Behavioral Sciences, (2013)

8. N. Ozkurt, D. Sari, A. Akdag, M. Kutukoglu, and A. Gurarslan, "Modeling of noise pollution and estimated human exposure around Istanbul Atatürk Airport in Turkey," Sci. Total Environ., vol. 482-483, no. 1, pp. 486-492, (2014).

9. M. S. Hammer, T. K. Swinburn, and R. L. Neitzel, "Environmental noise pollution in the United States : Developing an effective public health response," Environ. Health Perspect., vol. 122, no. 2, pp. 115119, (2014).

10. Bistrup, Marie Louise et al. "Health Effects Of Noise On Children And Perception Of The Risk Of Noise" (2001).

11. W. Babisch, B. Beule, M. Schust, N. Kersten, and H. Ising, "Traffic Noise and Risk of Myocardial Infarction," Epidemiology, vol. 16, no. 1, pp. 33-40, (2005).

12. E. A. King, E. P. Bourdeau, X. Y. K. Zheng, and F. Pilla, "A combined assessment of air and noise pollution on the High Line, New York City," Transp. Res. Part D, vol. 42, pp. 91-103, (2016).

13. N. M. Noor, H. Hamada, Y. Sagawa, and D. Yamamoto, "Effect of crumb rubber on concrete strength and chloride ion penetration resistance," J. Teknol., vol. 77, no. 32, pp. 171-178, (2015).

14. M. Gouveia, M. Borges, J. Costa, and A. V. Carneiro, "Burden of disease from hypercholesterolemia in Portugal.," Rev. Port. Cardiol., vol. 23, no. 2, pp. 255-270, (2004)

15. Popović, Zdenka, Luka Lazarević, Ljiljana Brajovic, and Milica Vilotijević, "The Importance of Rail Inspections In The Urban Area -Aspect of Head 
Checking Rail Defects", Procedia Engineering. (2015).

16. Savale, Pa."Effect of Noise Pollution On Human Being: Its Prevention and Control", Journal of Environmental Research and Development (2014).

17. S. A. Kudus, N. M. Bunnori, S. R. Basri, S. Shahidan, M. N. M. Jamil, and N. M. Noor, "An Overview Current Application of Artificial Neural Network in Concrete," Adv. Mater. Res., vol. 626, pp. 372-375, (2012).

18. S. Shahidan, N. M. Bunnori, N. Md Nor, and S. R. Basri, "Damage severity evaluation on reinforced concrete beam by means of acoustic emission signal and intensity analysis," in 2011 IEEE Symposium on Industrial Electronics and Applications, pp. 337-341, (2011).

19. K. Mehraby, "Numerical and Analytical Investigation in Radiated Noise by a ShockAbsorber," Int. J. Eng., vol. 26, no. 12 (C), pp. 15251534, (2012).

20. M. Attarchi, M. Mazloumi, S. K. Sadrnezhaad, A. Jafari, and M. Asadi, "Formation and rupture of carbonate film: an electrochemical noise approach," Anti-Corros. Methods Mater, vol. 56, no. 2, pp. 103109, (2009).

21. Maffei and Luigi, "Influence of The Design Of Railway Noise Barriers On Soundscape Perception" (2012).

22. Clairbois, Jean-Pierre and Massimo Garai. "The European Standards For Roads And Railways Noise Barriers : State of The Art 2015" (2015).

23. B. K. and C. English, "Environmental Noise Barriers. A Guide to their Acoustic and Visual Design, second edition," J. Sound Vib., vol. 329, no. 10, pp. 1982-1984, (2010).

24. E. P. D. EPD and H. D. HD, "Guidelines on Design of Noise Barriers," no. January, p. 4, (2003).

25. E. Van Haaren and P. H. Van Tol, "Validation of Ray Acoustics Applied for the Modelling of Noise Barriers," J. Sound Vib., vol. 231, no. 3, pp. 681-688, (2000).

26. P. Guidorzi and M.Garai,"Advancements in Sound Reflection and Airborne Sound Insulation Measurement on Noise Barriers." (2013).

27. K. Jambrosic, "In-Situ Measurement of the Absorption Coefficient." 1-8.

28. C. Heed, "Sound Absorption and Acoustic Surface Impedance." (1940).

29. E. M. Samsudin, L. H. Ismail, and A. A. Kadir, "A Review on Physical Factors Influencing Absorption Performance of fibrous Sound Absorption Material From Natural Fibers," vol. 11, no. 6, pp. 3703-3711, (2016).

30. C. Wang and J. Torng, "Experimental study of the absorption characteristics of some porous fibrous materials," Appl. Acoust., vol. 62, pp. 447-459, (2001).

31. R. P. Jaya, B. H. Abu Bakar, M. A. M. Johari, M. H. W. Ibrahim, M. R. Hainin, and D. S. Jayanti,
"Strength and microstructure analysis of concrete containing rice husk ash under seawater attack by wetting and drying cycles," Adv. Cem. Res., vol. 26, no. May, pp. 145-154, (2014).

32. S. R. Abdullah, W. R. Wan Zainal Abidin, and S. Shahidan, "Strength of Concrete Containing Rubber Particle As Partial Cement Replacement," MATEC Web Conf., vol. 47, pp. 2-5, (2016).

33. M. Abdul Rahim, N. M. Ibrahim, Z. Idris, Z. M. Ghazaly, S. Shahidan, N. L. Rahim, L. A. Sofri, and N. F. Isa, "Properties of Concrete with Different Percentange of the Rice Husk Ash (RHA) as Partial Cement Replacement," Mater. Sci. Forum, vol. 803 pp. 288-293, (2014).

34. T. Morimoto, "Sound absorbing materials," J. Acoust. Soc. Am., vol. 94, no. 5, p. 3037, (1993).

35. A. Amanda, J. B. Flóreza, and F. A. Moria, "Acoustic Characterization of Sugarcane Bagasse Particleboard Panels ( Saccharum officinarum L )," vol. 18, no. 4, pp. 821-827, (2015).

36. P. R. Tahir, A. M. A. Zaidi, N. Arsat, R. H. Mohamad Khairul Hadi Che Mohamad Khalib, and Z. F. Z. Abidin, "Potential Usage Of Agriculture Waste (Coconut Coir) For Sound Absorbing Material In Automotive Industry," (1991).

37. S. Ersoy and H. Küçük, "Investigation of industrial tea-leaf-fibre waste material for its sound absorption properties," Appl. Acoust., vol. 70, no. 1, pp. 215 220, (2009).

38. H. K. Kim and H. K. Lee, "Influence of cement flow and aggregate type on the mechanical and acoustic characteristics of porous concrete," Appl. Acoust., vol. 71, no. 7, pp. 607-615, (2010).

39. N. Md Nor, N. Muhamad Bunnori, A. Ibrahim, S. Shahidan, and S. N. M. Saliah, "An investigation on acoustic wave velocity of reinforced concrete beam in-plane source," in Proceedings - 2011 IEEE 7th International Colloquium on Signal Processing and Its Applications, CSPA 2011, pp. 19-22 (2011).

40. Koizumi, T., N. Tsujiuchi and A Adachi, "The Development of Sound Absorbing Materials Using Natural Bamboo Fibers, High Performance" WIT Press (2002).

41. A. Putra, Y. Abdullah, H. Efendy, W. M. Farid, M. R. Ayob, and M. S. Py, "Utilizing sugarcane wasted fibers as a sustainable acoustic absorber," Procedia Eng., vol. 53, pp. 632-638, (2013).

42. Stein, B. and Reynolds, J. S. Mechanical and Electrical Equipment for Building. New York: John Wiley and Sons (2000).

43. E. Setyowati and G. Hardiman, "The Acoustical Performances of Oyster Shell Waste Based Green Concrete Materials,” J. Eng. Technol., vol. 3, no. 3, (2015).

44. AL-Rahman, L.A. et al. Acoustic properties of innovative material from date palm fibre. American Journal of Applied Sciences, 9(9), pp. 1390-1395, (2012). 
45. H. K. Kim and H. K. Lee, "Acoustic absorption modeling of porous concrete considering the gradation and shape of aggregates and void ratio," $J$. Sound Vib., vol. 329, no. 7, pp. 866-879, (2010).

46. A. Putra, Y. Abdullah, H. Efendy, W. M. F. W. Mohamad, and N. L. Salleh, "Biomass from paddy waste fibers as sustainable acoustic material," $A d v$. Acoust. Vib., (2013).

47. L. Peng, B. Song, J. Wang, and D. Wang, "Mechanic and acoustic properties of the sound-absorbing material made from natural fiber and polyester," $A d v$. Mater. Sci. Eng., (2015).

48. S. Shahidan, R. Pullin, K. M. Holford, M. B. N, and N. Nor, "Quantitative Evaluation of the Relationship between Tensile Crack and Shear Movement in Concrete beams," Adv. Mater. Res., vol. 626, pp. 355-359, (2013).

49. S. Shahidan, H. B. Koh, A. M. S. Alansi, and L. Y. Loon, "Strength Development and Water Permeability of Engineered Biomass Aggregate Pervious Concrete," MATEC Web Conf., vol. 47, pp. 2-7, (2016)

50. Wassilieff, C. Sound absorption of wood-based materials. Applied Acoustics, 48(4), pp. 339-356, (1996).

51. Z. Hong, L. Bo, H. Guangsu, and H. Jia, "A novel composite sound absorber with recycled rubber particles," J. Sound Vib., vol. 304, no. 1-2, pp. 400406, (2007).

52. S. Mahzan, a M. A. Zaidi, N. Arsat, M. N. M. Hatta, M. I. Ghazali, and S. R. Mohideen, "Study on Sound Absorption Properties of Coconut Coir Fibre Reinforced Composite with Added Recycled Rubber," Integr. Eng., no. Mechanical, Materials and Manufacturing, pp. 1-6, (2009).

53. H. S. Seddeq, "Factors Influencing Acoustic Performance of Sound Absorptive Materials," vol. 3, no. 4, pp. 4610-4617, (2009).

54. DuPont, "Acoustic: Different kinds of materials for traffic noise barriers," Urban Acoust., (2009).

55. N. Cooperative, "Guidelines for Selection and Approval of Noise Barrier Products Final Report," no. July, (2008).

56. J. Clairbois, foort de Roo, M. Garai, M. Conter, J. Defrance, crina A. Oltean, and C. Durso, "Guidebook to Noise Reducing Devices optimisation," no. December 2012, pp. 1-56, (2013). 